\title{
Mobility types, transnational ties and personal networks in four highly skilled immigrant communities in Seville (Spain)
}

\author{
Romina Cachia \& Isidro Maya Jariego \\ University of Seville
}

In this study, we explore how different mobility patterns influence the composition and structure of the transnational social support networks and how personal networks allow us to elicit insightful data of mobile individuals. Ninety-five mobile individuals were selected from four distinct communities based in Seville (Spain), namely: Erasmus students, Flamenco artists, musicians from the symphonic orchestra and partners of European Commission researchers. Data were collected through an electronic survey sent by email with multiple name generators and a structured face-to-face interview utilizing a network visualization tool, VennMaker. Two distinct methods, namely qualitative case studies and cluster analysis were used to characterize mobility types. Findings reveal a heterogeneous foreign population, in which different forms of mobility are reflected in the personal networks of mobile individuals. Respondents who were settled in the city were more likely to have networks in which social support was mainly derived by hosts and people in the host location and with whom they communicated predominantly through face-to-face communication. Those who were in the host location for a study exchange, knowing that return to the county of origin is imminent were more likely to have networks linked to the home location. They relied heavily on strong transnational ties in the home country using social media to sustain their relationship. Respondents with an itinerant mobility profile, also had networks dominated by strong transnational ties, however, such ties had a higher degree of geographical spread due to previous international mobility. Participants who had a high number of hosts in the network but low connection between the ties were more likely to be linked to a specific subculture in the host society. The integration in the host location follows a different pattern to other settled individuals, mainly because their connection in the city tends to be community specific.

\section{Author information}

Romina Cachia. Universidad de Sevilla, Departamento de Psicología Social, Laboratorio de Redes Personales y Comunidades. Sevilla, España.

\section{rcachia@gmail.com}

Isidro Maya Jariego. Universidad de Sevilla, Departamento de Psicología Social, Laboratorio de Redes Personales y Comunidades. Sevilla, España.

isidromj@us.es 
Address: Facultad de Psicología. Calle Camilo José Cela s/n. Universidad de Sevilla. 41018 Sevilla (Spain).

This work was partially funded by a Grantholder contract from the Institute of Prospective Technological Studies (IPTS), Joint Research Centre, European Comission.

\section{Highlights}

- Compares patterns of mobility and relational integration of four communities of foreigners in Seville (Spain).

- Examines the relevance of length of residence and expectations of living in the host society for immigrants.

- Cluster analysis identifies four types of networks, namely: dense network, host network, distant network and sparse network.

- Academic short stays (round trip), and roaming from one country to another are associated with greater connectivity with the country of origin.

- Both the length of stay and the expectations of living in the host country are associated with more connections with individuals in the host location. 


\section{Introduction}

Marie, a French student arrived in Seville in September 2011 as an Erasmus student. Iko moved from Japan to Seville, five years earlier to study flamenco dancing. That same year, Sofia, an Italian artist moved to Seville with her husband, after he obtained a research grant to work for a European Commission (EC) research institution. Sofia, a lover of classical music knew Boris: a Bulgarian violinist of the symphonic orchestra in Seville. Boris moved to Seville to work for the orchestra 20 years ago. The four share the same city. Their move to Seville was intentional. All are highly skilled and educated, but they differ in their mobility patterns.

Mobility, in essence, is moving from one residence to another. However, there is a wide variety of types of mobility depending on the distance, tempos and rhythms, as well as differences in the degree of stability and the expectations of permanence (Collins, 2011; Griffith, Rogers, \& Anderson, 2013; Robertson, 2014; Sheller \& Urry, 2006). Initially, three core types have been distinguished for international migration, namely temporary labor migrants, settler-migrants and refugees (King, 2012). However, the past decades have seen a proliferation of new types of approaches that acknowledge 'transnationality and temporariness of diverse kinds of migrants' (Robertson, 2014, p. 3; cf. King 2012). Among these other forms are round trips (such as short stays for work or study), or new modalities of international work in continuous mobility (from international commuters to frequent extended business trips; Mayrhofer, Sparrow \& Zimmermann, 2008).

The degree of mobility, whether a migrant is seemingly settled in the new country or engaged in continuous transnational circulation has a significant influence on the transnational space developed (Dahinden, 2010), which can have consequences for the provision of social support and for individual well-being. Past research has had difficulties to capture the concept of transnational space empirically, but personal network analysis has been suggested recently as particularly appropriate to describe the transnational space that people develop individually (Maya-Jariego, 2004; Molina, Peterman \& Herz, 2014), as well as the provision of social support.

This paper examines how different types of mobility in different community settings are reflected in the composition and structure of the support network. Specifically, we expected that depending on the type of mobility, respondents differ in the way they reconfigure their personal networks to stay connected with close ties that are far away, fabricate a network of local ties and combine local and distant ties in a personal network on which they rely for different kinds of support.

For this aim, we selected four groups of immigrants within a highly qualified and skilled population in a single place of residence that allow us to distinguish between temporary stays with shortterm return (Erasmus students); continuous displacements, in itinerancy (partners of workers of the European Community); recurring temporary stays (Japanese flamenco dancers); and permanent settlement on arrival (musicians of the symphonic orchestra). Ninety-five foreigners 
residing in Seville (Spain) were recruited and interviewed from the above-mentioned communities. Utilizing the community as a framework of analysis allowed us to extract four types of possible mobility patterns amongst a specific type of population. We compared the composition and structure of their support networks and illustrated the differences with case studies.

The paper is structured as follows. First, we explore how changes in migration have prompted the need for a transnational perspective, especially in the context of understanding the social support network for mobile individuals. Second, we present the data, instruments and methods utilized for this research. Third, we present a descriptive analysis of the relation between transnational social support networks and mobility patterns for all 95 cases, followed by a presentation of four case studies to visually illustrate some major differences between the composition and structure of personal networks. Fourth, we utilize a cluster analysis to examine typologies based on indicators of network composition and structure. The article ends with a discussion on the findings.

\subsection{Transnational personal networks}

Mobility has provoked a wide array of debates and research on the transnational dimensions of migrants' experiences (Vertovec, 2003). Unlike previous generations of migrants, migrants now stay in touch on an everyday basis with the people they leave behind (Diminescu, 2008), and although mobility may initially disrupt the social support network, it seems that more and more mobile individuals use different tools through which they sustain social ties on a distance (Axhausen \& Frei, 2008; Boase, Horrigan, Wellman, \& Rainie, 2006; Castells, 2000; Urry, 2007; Wellman, 1996).

Western individuals routinely form social connections and communicate with people and institutions who are far away, continuously participating in ephemeral configurations of togetherness in different spaces. Meaningful social relations are increasingly widespread across the globe and no longer ever entirely linked to the location. In the early days of social media expansion, Albrow (1997) already found in his study in an inner London borough that respondents hardly knew their neighbors, because their paths rarely crossed, but they kept daily contact with people across the globe.

As more people live geographically apart, those who are close emotionally are possibly geographically far away. In order to identify transnational formations in a specific place, geographical information about the ties' location is crucial (Featherstone, Phillips, \& Waters, 2007). Personal networks are ideal because they can measure the different geographical locations where an individual's social ties reside and also where the movement of the individual takes place. Viry (2012) found that the further away people live from where they lived when they were 14 years old, the more geographically dispersed their networks were and the farther their social ties tended to live from one another. The ease of maintaining multiple social relations across time and space through different interactive media have some implications on how strong and weak ties (Granovetter, 1973) are managed. The ways we make absent individuals present are varied and complex (Licoppe, 2004), as different strategies and resources are used to 
maintain strong ties over long distances (Larsen, Urry, \& Axhausen, 2006; Urry, 2007; Wellman, 2001). Although far away emotional ties can be kept close through technology-mediated communication, distance still matters (Axhausen \& Frei, 2008; Licoppe, 2004). People travel very often, spending considerably amount of money and time on the road to meet physically with their family and friends. Transnational ties are sustained and enforced through mobility, where 'roots and routes' (Clifford, 1994) are present in different transnational formations (Dahinden, 2010). This need to travel, given the wide array of opportunities of new communications technology for virtual proximity, is based on the idea that a tie remains active through co-presence (Larsen, Urry, \& Axhaussen, 2006) and "meetingness"1 (Urry, 2003).

The recognition by migration research that migrants are "multiply situated, with relations stretched across space" (Geddie, 2013, p. 198) has prompted the need for a transnational perspective on migration. A broader understanding of migration, which also takes into account ongoing movement between different locations and with different duration, allows us to see migration as complex process with different spatial-temporal dimensions (Malmberg, 1997). Static or sedentary structures, which have traditionally defined western society, such as a life-long residence and stable employment are now replaced by a new defining characteristic, mobility (Urry, 2000, 2007). This has led to a diversification and intensification of migration, especially within the European borders. In general, research covers three major types of migration, namely: temporary labor migrants, settler-migrants and refugees (King, 2012), however, over the past decades a proliferation of new types of approaches acknowledging the diversity of migration can be observed (King, 2012; Robertson, 2014).

Although there is a rapidly increasing body of literature addressing different areas of intentional migration, namely: mobility of knowledge workers (Beaverstock, 1994), international student mobility (Bilecen, 2014; King, Findlay, \& Ahrens, 2010), temporary and circular migration (Parreñas, 2010), it focuses more on the dynamics of acculturation, the migratory project and the influence of political and cultural factors and less on comparisons between various forms of geographical mobility (Maya-Jariego \& Armitage, 2007) ${ }^{2}$. One of the few exceptions is a comparative study by Kyle (2000) of four Ecuadorian migration communities. In this study, Kyle explores how ethnic identity shapes divergent patterns of transnational migration to New York and Europe. Using everyday networks of social and ethnic relationships, Kyle found that despite similar socio-demographic characteristics, the respondents had geographic diverse experiences. Another study that distinguishes between different patterns of mobility among migrant groups is the one by Dahinden (2010) based in Switzerland. Comparing cabaret dancers, Albanianspeaking migrants and Armenians, Dahinden identify four types of transnational formations based on the juxtaposition of two mobility dimensions: the type of mobility and the locality.

\footnotetext{
${ }^{1}$ This neologism was introduced by Urry (2003) in the studies of global mobility: This term represents the persistent need to meet face-to-face, even when much of the activities of social life are more and more networked and at-a-distance.

2 In fact, if we look at geographical mobility, international migration can be understood as a form of ecological transition that is at least partly comparable to move house, change the city of residence, or even commuting between different cities.
} 
As we have seen from the above literature, the geographical dispersion of the social ties, the way mobile individuals sustain their relationships through mediated communication and periodic travel, the incorporation of local ties and the way different kinds of relations (strong and weak) are managed in different social spaces are all indicators of different kinds of mobility. As mobility becomes more diverse, there is an increasing need to capture such diversity in transnational migration research. In this study, we assume that the transnational personal networks forged are related to type of mobility undertaken by the respondents, taking into account an indispensable factor in mobility, social support.

\subsection{Social support in the context of transnational mobility}

Social support is defined as 'the existence or the availability of people on whom we can rely, people who let us know that they care about, value and love us' (Sarason, Levine, Basham, \& Sarason, 1983, p.127). The concept is used to describe attachment, affiliation and social integration resources, as well as to explain how individuals feel empowered through the provision of social relations (Barrera, 1980). Research has shown that people facing emotional problems and in moment of crisis resort primarily to their intimate ties, rather than to professional mental health services (Caplan, 1974; Cassel, 1974; Cobb, 1976)

Social support does not only refer to emotional support though, it refers to all tangible and intangible resources that individuals obtain from their network of relationships (Song, Son \& Lin, 2011). It is a concept of a multidimensional nature in which there is usually a distinction between emotional, instrumental and informational support (Barrera, 1980; Burt, 1984; Fischer, 1982; Marin \& Hampton, 2007; van der Poel, 1993; Wellman, 1979; Wellman \& Wortley, 1990). Individuals tend to have a mixture of specialized - providers of one type of support - and multiplex ties - providers of different types of support (Hennig, 2007). Emotional support is more likely to be provided by strong ties, while weak social bonds seem more important in providing advice and information (Tardy, 1985).

The exchange of help, affection, and advice has potentially positive effects on psychological wellbeing, and contributes to stress reduction (Song, Son \& Lin, 2011). However, the complexity of the concept entails the need to address the overlap between social integration, structural properties of the network, and support functions (Maya-Jariego, 2006; Song, Son \& Lin, 2011). In that sense, although a large number of studies analyze received support (Song, Son \& Lin, 2011), the perception of available support has been revealed as a robust indicator, with stronger empirical evidence when studying stress, psychological well-being, morbidity and mortality (Maya-Jariego, 2006; Veiel \& Baumann, 1992).

With regard to immigrant populations, Maya Jariego (2006) identified that social support studies focus on three main categories: (1) availability of social support following mobility; (2) examination of the composition of the network, especially the presence of family members; (3) changes in the immigrant's personal environment experiences over time in the host location. Recent immigrants tend to be characterized by: a reduction, at least temporarily, in the amount of perceived social 
support; a concentration of support functions by fewer providers; a higher rate of change in personal relations, with an active process of rebuilding the size, structural configuration and functions of the personal networks; and an increase, at least temporarily, of the heterogeneity of the composition of the support system (Maya-Jariego, 2006). This affects the reorganization of support resources: after geographic relocation, personal relationships maintained with the place of origin are not accessible to provide social companionship or instrumental help, and consequently focus especially on providing emotional support (Herz, 2015).

The geographical dispersion of social relations makes connections weaker and more transient (Wellman, 1999). However, mobile individuals tend to have transitive ties that survive great spatial distances and seemingly this does not impede the provision of social support (Viry, 2012). While tangible social support is mainly provided by contacts at short distances, geographical distance seems to have little effect on intangible type of support, such as, emotional support (Dahinden, 2010; Herz, 2015; Mok \& Wellman, 2007; Ryan, Sales, Tilki, \& Siara, 2008; Viry, 2012).

Mobile individuals are typically connected to strong and enduring transnational ties and new, weaker ties in the host location, both of which are important for reducing mobility-related stress which can cause negative effects on psychological well-being (Magdol \& Bessel, 2003). Taking into account different types of support provided by different alters provides a more comprehensive understanding of the social support network. Accordingly, this research examines the multiplicity of support in different locations and by different alters through the composition of the personal network.

In the case of people who move geographically, we can also expect that mobility affects the structure of the networks, in particular structural cohesion (density, degree, centrality and centralization) and fragmentation (components) of the networks. Personal networks of individuals with more geographical displacements typically have higher levels of centralization than the rest of the population, and eventually also tend to be divided into components (Maya-Jariego \& Holgado, 2015), as is confirmed by specific indicators. Mobility often results in a lower degree centrality and a higher proportion of isolated nodes (Hayne \& South, 2005), lower density (Fischer, 1982), higher nodal betweenness (Maya Jariego \& Armitage, 2007), a greater geographical dispersion of social ties (Magdol, 2000) and a relative increase in non-kin ties (Degenne \& Lebeaux, 2005). The average nodal betweenness of personal networks affects the changes in the entire social network, as has been found in a longitudinal study, amongst a cohort of students moving from high school to university and initiating a metropolitan lifestyle, commuting everyday (Maya-Jariego, Holgado \& Lubbers, 2016).

\subsection{This study}

In recent years, mobility has not only increased in number but also in its variety. Those diverse modes of geographic relocation may be key in the way individuals reorganize their personal networks. In this research we describe and compare the personal networks of immigrants in temporary stays (Erasmus students), in itinerancy between different labor destinations (partners 
of European Community workers), in repeated and/or medium to long-term stays (apprentices of flamenco) and long-term settlement in the country of destination (musicians of the symphonic orchestra).

In this work, we utilize personal networks to locate and map out the social ties respondents rely on for social support. The data have been collected through qualitative interviews and participatory network delineation instrument. We analyze differences between types of mobility in the composition, functionality and structure of the networks, first with bivariate analysis (per network characteristic) and then for all network characteristics combined in a typology. Last, we illustrate each pattern with a typical case study. These data serve to complement the typologies with insightful information on the patterns of integration and network strategies used by the respondents, taking advantage of the benefits of combining qualitative approaches with network analysis (Hollstein, 2011; Gamper, Schönhuth, \& Kronenwett, 2012).

\section{Methods}

\subsection{Sample}

For the aim of this study, empirical data were collected in 2012 from 95 mobile individuals in Seville, Spain. Respondents were selected from four communities of foreigners in Seville, for whom mobility was voluntary and intentional. The four communities were Erasmus students ( $n=33$ ), partners of EC researchers ( $n=25)$, Japanese flamenco artists $(n=19)$ and musicians from the symphonic classical orchestra $(n=18)$. The communities were selected on the basis that they represented different types of mobility in a single city. Erasmus students provided an opportunity to study short-term return mobility, knowing that at the end of the academic year they would go back. Partners of researchers were unique in encompassing a circular type of mobility, in which residence in Seville was one location in different mobile trajectories. The Japanese apprentices of flamenco often make recurrent visits, of medium and long term. The musicians from the orchestra provided an opportunity to study long-term residential mobility and settlement in the host location.

In each of these communities, participants were selected through snowball sampling. To help mitigate snowball sampling limitations (Salganik \& Douglas, 2004), seeds were selected from distinct social circles in each community identified at the beginning of the study. These social circles were identified through three sources: attendance at events organized by communities; formal requests for participation within the community; and social media. Snowball sampling led to more positive response within the communities were some form of trusted interpersonal relationship already existed, namely the orchestra and researchers' partners.

In total, 195 respondents were recruited and invited to participate in the study on a voluntary basis, out of which 100 accepted to be interviewed. For the analysis, data from 95 interviews were used due to uncompleted and incorrect data in five of the interviews. All respondents had lived in Seville for at least six months, a threshold we used, so as to allow some development in the 
personal network in the host location. Interviews lasted on average around an hour and 15 minutes. Among five of the respondents from the orchestra, a partial match (of on average $16 \%$ ) between some of the alters was observed. The other cases showed no overlap.

The demographics of our sample are presented in Table 1. Female participants dominated the sample. Erasmus students were all under 30, while respondents from the Flamenco community, partners of researchers and members of the orchestra were more diversified, with middle-age respondents dominating. The oldest respondents were generally members from the orchestra. Whereas Erasmus students were mainly single, partners of researchers and orchestra members were more likely to be married. The majority of partners of researchers were unemployed (32\%), some were working (24\%) and some studying (16\%). The rest were either taking some time out of their careers to take care of young kids or they had asked for a special leave to be able to travel with their partner. The majority of the Japanese Flamenco artists and Erasmus students lived with flat mates, while partners of researchers and orchestra musicians lived with their partner and with their children.

\subsection{Measures}

Data for this study were collected in two phases. Upon acceptance to participate in the study, respondents were sent an electronic document by email, which they were asked to complete and send back to the researcher. In the second phase, a structured face-to-face interview was conducted. Data collection from the two modes was separated by no longer than a week, with all the respondents participating in both phases.

\subsubsection{Name Generators}

The first phase of the data collection consisted mainly in a name generator instrument developed in and adapted from previous research (Burt, 1984; Fischer, 1982; Marin \& Hampton, 2007; van der Poel, 1993; Wellman, 1979; Wellman \& Wortley, 1990). Using multiple name generators, in which different types of social support were identified, resulted in a more accurate representation of the total social support network (Marin \& Hampton, 2007; van der Poel, 1993).

\section{HERE TABLE 1}

Respondents were instructed to list 30 people on whom they can rely for: 1) emotional support; 2) instrumental support; 3) social companionship; 4) co-presence: people who visit on special occasions; and 5) other important people in their lives. For each type of support, specific questions were asked. A table with 30 rows (to list alters) and 5 columns (a column for each type of support) was used. Whereas the names of people were to be listed vertically, a tie providing more than one type of support could be listed again horizontally in different types of support. A tie listed in different columns, twice or more was later classified as a multiplex alter. The instrument is based on perceived social support, as opposed to received social support (Maya-Jariego, 2006; Molina, Fernandez, Llopis, \& McCarty, 2008; Veiel \& Baumann, 1992). We opted for perceived support, given that received support would have created a bias, especially for respondents who were in 
Seville for a relatively short period. The fixed-choice of 30 alters aimed at delineating a personal network large enough for structural network analysis (McCarty, 2002), but also feasible to administer and not too complex, to interact with the network visualizations.

\subsubsection{Face-to-Face interview}

The second phase consisted of computer-assisted face-to-face interviews utilizing the software VennMaker ${ }^{3}$ (Schönhuth, Kronenwett, Gamper, \& Stark, 2012), semi-structured interviewing and a paper instrument. First, respondents were assisted to develop a visualization of their personal networks in VennMaker using the 30 names they listed in the first phase of the data collection. The participatory network visualization, as opposed to the construction of a binary matrix using structured interviewing, makes it easier for the respondents to create their own adjacency matrix, and hence, indirectly reduces error (Gamper, Schönhuth, \& Kronenwett, 2012). Moreover, it is less tedious (McCarty, Molina, Aguilera, \& Rota, 2007), allows the researchers to work closely with respondents (Hogan et al., 2007) and it is better evaluated by the interviewees, even if takes time (Herz \& Gamper, 2012) because it adds an interactive element to the interview.

A paper instrument was used to collect socio-demographic data of the respondents and the alters, and these data were later added to Vennmaker. Considering the two phases of data collection, a variety of name interpreters were collected (Table 2), including the geographical location, nationality, duration of tie and type of relation. Support provision could be derived from the name generators themselves.

\section{HERE TABLE 2}

\subsection{Analysis}

For a structural analysis of the network data, the adjacency matrix was exported to Ucinet (Borgatti, Everett \& Freeman, 2002). Four centrality measures were calculated, namely: degree centrality, closeness centrality, betweenness centrality (Freeman, 1979), and eigenvector centrality (Bonacich, 1972). Average indicators of each centrality measure were computed as a proxy for the structural properties of each personal network (Dominguez \& Maya-Jariego, 2008). By definition ego is connected to each and every alter and its presence can strongly bias structural measures, in particular centrality measures (Degenne \& Lebeaux, 2005; McCarty \& Wutich, 2005), hence it was eliminated from all the measures. Centrality measures were used to identify patterns of interconnectedness between alters in the personal networks.

In order to study bivariate relations between the mobility profiles on the one hand and network on the other, we used analysis of variance. All variables used were tested for normality. One-way Anova (Scheffé intergroup means) was used for normally distributed variables ( $F$ scores) and the Kruskal-Wallis test (H scores) was used for the non-parametric variables. For the non-parametric

\footnotetext{
${ }^{3}$ http://www.vennmaker.com/?lang=en
} 
variables, follow-up tests to evaluate pair wise differences among the four communities were used, controlling for Type I error across tests by using the Bonferroni approach.

We then proceeded with clustering the network characteristics to create network profiles. The development of clusters is an efficient strategy to describe personal networks through typologies (Maya-Jariego, 2002, 2003). Building typologies, from a set of indicators, serves to identify common configurations of these indicators or "types" of personal networks (Bidart, Degenne \& Grossetti, 2011; Lubbers, Molina \& McCarty, 2007; Maya-Jariego, 2006; Maya-Jariego \& Holgado, 2015). In this study, we make a classification using indicators of composition and structure of the personal network. The criterion variables selected were: average closeness centrality (which provided significant differences in previous analyzes), the number of friends (which indirectly differentiates the degree of family composition of the network), the number of Spanish (to assess the degree of local integration), and the number of alters living in the country of origin (which reports the transnational nature of the networks). The variables selected were those that, according to the previous descriptive analysis, allowed a better differentiation between the respondents and showed a lower collinearity with the other variables.

We used k-means cluster analysis for the construction of clusters. After careful consideration between different numbers of clusters, we opted for four, obtaining a balanced distribution of subjects across categories. A maximum of 10 iterations was established with a convergence criterion of 0.02 . The cluster centroids of each variable are presented in Table 4. The terms used to refer to the clusters are for descriptive purposes given that they only refer to one distinctive property of the clusters.

To describe individuals belonging to each category, we crossed (with crosstabs chi-square), types of networks with the demographic, socio-economic, and mobility variables collected in our study.

Last, in order to illustrate differences in network composition and structure across the different mobility patterns, typical cases of each type of mobility were selected and the visualization of their network shown. Visualizations serve to show the structure of the network, in which groupings and the bridges between the groups can be identified with little effort, as well as to allow for exploration of the relations (McCarty et al., 2007). The visualization of personal networks has proven to be a useful device to guide qualitative interviews and obtain biographical information of respondents (Hogan, Carrasco \& Wellman, 2007; Maya-Jariego \& Holgado, 2005; Molina, Maya-Jariego \& McCarty, 2014).

\section{Results}

3.1 Descriptive analysis of transnational social support and mobile patterns

First, we study bivariate relations among network characteristics and mobility profiles (Table 3). Table 3 lists the mean variable score for each community and the intercommunity differences and their significance. Of the 12 network characteristics, eight differed significantly in relation to the type of community mobility profile. Across the four profiles, we observed differences in both the 
composition and the structure of the personal network. In terms of the composition, we noted differences in the number of alters listed who: reside in the host location; live in the country of origin; are of Spanish nationality; are co-nationals; friends; the respondents have known in the past five years; they have known over 20 years. Differences between the four communities were also observed in the structure of the network, mainly in the closeness average centrality of their network ${ }^{4}$. The type of communication used for frequent interaction (daily and weekly) also differed significantly between the four communities.

\section{HERE TABLE 3}

When we study the differences across the four communities, we find the following. Respondents from the Flamenco community differed in having personal networks dominated by individuals from the host country, alters living in the host location and ties they got to know in the past five years. Their ties were more likely to be dispersed and less connected to each other through shorter paths. Japanese respondents relied more on face-to-face contact to communicate frequently with their support network and less on technological media.

Erasmus students were more likely to rely on support from transnational ties in place of origin and co-nationals. Their personal networks were mostly made up of friends and of people they got to know recently. Their personal networks had the lowest number of ties living in Seville and also the lowest number of Spanish people. They also differed significantly in the use of media. Erasmus students communicate with half of their social ties through social networking sites (SNS) and used Voice over Internet Protocol (VoIP) more than any other of the other groups ${ }^{5}$. Interestingly, they listed the lowest number of alters across the four communities with whom they communicated frequently using email, seemingly suggesting that email has been displaced by SNS as a major source of communication with the support network of young people.

Partners of researchers were also more likely to mention more people in their country of origin and co-nationals. These respondents would derive support from both recently known ties and also ties they have known for a very long time. In terms of structure, these networks were more likely to be interconnected. They communicated with their ties mainly through email. Across the four communities, these respondents listed various ties with whom they hardly communicate faceto-face.

The major providers of social support for musicians from the orchestra are people from the host country and people living in the host location. Musicians differed from other groups in listing few co-nationals and friends as providers of social support. Almost a fourth of the personal network is

\footnotetext{
${ }^{4}$ Average closeness centrality ranged from 4.25 to 72.98 , where the possible range is 0 to 100 . Standard deviation indicates that of the four measures, closeness centrality varies the most among the respondents. This result is consistent with previous studies (Lozares et al., 2013; Maya-Jariego \& Holgado, 2015; McCarty, 2002). Closeness is usually highly positively correlated with degree and eigenvector centrality, and inversely correlated with betweenness. In aggregate, it is a generic indicator (or proxy) of the structural cohesion of the network.

${ }^{5}$ Age seems key to the use of SNS in our sample. Young Erasmus students used SNS to communicate even with people locally, as a way to keep in touch and to know what is happening. On the contrary, middle-age and older respondents relied more on the phone with local contacts and used SNS with oversees contacts.
} 
made up of ties they have known over 20 years, while people they got to know recently make up only a small proportion of their network. These respondents also tended to have networks with a high closeness centrality. They communicated frequently with their support network through faceto-face communication and through mobile phone and hardly used SNS to communicate with their contacts.

\subsection{Cluster Analysis}

\section{HERE TABLE 4}

Based on the cluster analysis, we created a typology of four network profiles.

The Dense Network ( $n=13$ ) profile is mainly characterized by respondents whose social support alters are well connected among themselves and by a high proportion of the network residing in the country of origin and a medium number of hosts. Respondents with this profile were mainly middle-aged 41-60 (46\%), followed closely by ages 21-40 (39\%). They had either moved for work or studies and were either planning to stay in Seville a few more months or indefinitely.

Respondents with a Host Network $(n=21)$ profile were more likely to rely on hosts for social support and less like on ties in the country of origin. Respondents with this profile were more likely to be older and had higher education (with a majority having a post-graduate degree). The majority had lived in the host location for more than 10 years (57\%) or between one and five years (33\%). This cluster is clearly differentiated by having respondents who live with their family and plan to live in Seville indefinitely. Most of these respondents have moved to Seville because of work, and the majority was employed.

The third cluster is the biggest and can be described as the Distant Network $(n=34)$ profile, where respondents listed many alters living in the country of origin and consequently, few Spanish alters. They also nominated many friends. Participants with this profile were more likely to have lived in Seville for less than a year, and hardly any respondents planned to live in Seville indefinitely. The majority were students aged between 21-40 living with flat mates.

The Sparse Network ( $n=22$ ) profile is characterized by respondents with low centrality networks and a high proportion of alters living in country of origin and medium number of hosts. These respondents were more likely to be divorced or separated and were planning to move either in the next few months or in the next 1-5 years. Respondents with this type of network were more likely to be studying.

Network profiles differed significantly in terms of the main reason for moving to Seville, $X^{2}$ (12, $N=90)=23.28, p=.03$; duration of stay in Seville (measured in intervals), $X^{2}(9, N=90)=34.79, p$ $<.01$; how long they planned to stay in Seville, $X^{2}(9, N=90)=31.16, p<.01$; and with whom they lived in Seville, $X^{2}(9, N=90)=34.42, p<.01$ (Table 5). As indicated above, there were also differences with respect to individual characteristics: the clusters differed in terms of respondents' age ranges, $X^{2}(9, N=90)=34.46, p<.01$; legal status, $X^{2}(12, N=90)=27.22, p<.01$; education, 
$X^{2}(9, N=90)=17.45, p<.05$; and work status, $X^{2}(9, N=90)=31.83, p<.01$. In terms of frequency of different modes of communication, we only observed a significant difference for communication through SNS, $X^{2}(3, N=90)=12,24, p<.01$. The network profile of the respondents was positively related to the type of mobility pattern, $X^{2}(9, N=90)=37.91, p<.01$. Japanese flamenco respondents were more likely to have sparse networks $(44 \%)$ and less likely to have distant networks. A large majority of Erasmus students had a distant network profile, and a small portion of students had a Sparse network profile. Partners of IPTS researchers were more likely to have Distant and Sparse networks profiles. Musicians from the orchestra were more likely to have the Host type of network profile, followed by the Dense network profile (Figure 1).

\section{HERE FIGURE 1}

In line with our expectations, the organization of support resources seems clearly associated with the type of mobility. We observed that a relation exists between both network composition and network structure and the type of mobility that frames our respondents. Musicians and flamenco artists dispose of support networks based in Seville, in which a high number of Spanish people have been incorporated in their network. In contrast, respondents who have either moved recently or who have moved for a short period, as in the case for most Erasmus students and researchers' partners tended to remain highly linked to alters in their country of origin and co-nationals. Their networks are highly transnational reflecting the transit nature of their mobility.

\section{HERE TABLE 5}

\subsection{Case studies of mobility typologies}

The preceding analyses indicate a relation between mobility profiles and the composition and structure of personal networks. In this section, we explore four typical cases that illustrate on a visual level the distinct personal networks depending on the type of mobility. The four cases were selected after the comparative analysis of the previous sections, trying to represent the most characteristic elements of each group reported above. The examples were chosen so as to adequately represent the type of structure and composition of personal networks of each collective. For each case, we use a network visualization that we created post-interview and additional data from the interviews. Each graph includes: 
- The 30 alters mentioned by the respondent. The respondent is excluded from the network map.

- Ties between the nodes indicate which alters know each other.

- The color of the nodes illustrates the nationality of alters: red for hosts; blue for conationals and green for other nationalities.

- The size of the nodes reflects the multiplexity of the social support provided by alter: the more types of support provided by the same alter, the larger the node ${ }^{6}$.

- The three sections of the network defined by the pie chart indicate the location of residence of alters during the time of the interview: pink for host location, the light blue for country of origin and light green, for other locations of residence.

Yoko, flamenco dancer: Figure 2 shows the personal network of Yoko, a 35-year-old Japanese flamenco dancer, who moved to Seville ten years ago to pursue her training in Flamenco dancing. Her move to Seville was relatively easy, mainly because a former teacher of hers in Japan introduced her to people in Seville. First she made several temporary stays of less than a year before settling in Seville on a more long-term basis. Yoko studies flamenco dancing during the day and works in the evenings at the reception of a typical flamenco tablao (a small theatre where flamenco is performed, mainly for tourists). Very few of our respondents from the flamenco group worked as artists and the ones who did, seemed to have exceptional respect from the community. Flamenco is a tightly-knit community, with ease of access the outer periphery, mainly through flamenco classes, but particular difficulty to access the core of the community, especially by foreigners, except for remarkably talented artists. Jobs varied from secretaries, to language teacher to fitness instructor, amongst others.

Most alters in Yoko's network provide a single type of support: specialized support. Support is derived equally from people in Seville, who tend to be natives of Spain, and people in the country of origin, entirely co-nationals. The absence of co-nationals in the host location is unique to this profile. In the case of flamenco artists, alters in Seville were more likely to be community-specific, that is, ties to other people in the flamenco industry. Yoko's network structure is clearly defined in two locations, Seville and Japan, but there is little contact between the two locations. Indeed, the network shows less density than in the other communities, with fewer alters knowing each other and the absence of bridges between the subgroups in her network. Her most central alter (\#151 in Fig. 1) is her boyfriend who plays an important role in her network bridging the people in the different locations.

Despite having a Spanish boyfriend, Yoko feels that Seville has layers of groups, some of which, she will never have the chance to be part of. Although she is deeply rooted in the flamenco world

\footnotetext{
${ }^{6}$ In personal networks, multiplexity can be considered as a property of relations between alteri or as a property of the providers of social support (Maya-Jariego \& Holgado, 2015). In the literature of social networks, the strength of the relationship is usually represented with the thickness of the link. However, the number of types of support that each alter provides to ego introduces the point of view of the respondent (represented in this case with the size of the node). Thus, in the same representation we can have the strength of relationships between all actors and the importance attached by ego to each of them in terms of the emotional, instrumental and informative support resources that they provide.
} 
and knew and relied on a high proportion of locals for social support, as yet, Yoko operates socially on the periphery of the city. Given her visa is renewed, Yoko has no intention to move back to Japan. As another Japanese respondent told us, "Seville is a very calm city in comparison with Japan... And although, there are many things which bother me about this city, the way of living here is freer than in Japan" (Flamenco community \#51, female, 33 years). Yoko travels to Japan to see her family and friends once every two years.

\section{HERE FIGURE 2}

Margot, Erasmus student: Margot is a 20 year old southern European student, who has lived in Seville for six months and will go back to her country of origin at the end of the academic year (Figure 3). Her move to Seville is her first residential move. As is typical of networks of recently arrived migrants', her network is dominated by strong ties, mainly co-nationals, in her home location in her country of origin. Margot has an active social life in Seville, in particular with the foreign student cohort, whom she relies on for instrumental and socializing support. The significance of the social relations established in the host location were echoed in a statement of one of the other respondents about his relations established in Seville: "Sentimentally, I made good friends here, and coming back to my country it will be a different kind of relationships" (Erasmus student \#12, male, 21 years).

Margot's network is made of interconnected groups with little connection amongst each other. A major connection between the host location and the country of origin is a co-national friend (alter 19), who she knew from her dancing classes prior to her move to Seville. Margot typically displays a network in which an imminent mobility is foreseen. The network is divided into two social spaces. Strong multiplex ties are based in the country of origin and weak specialized ties are established in the host location.

\section{HERE FIGURE 3}

Celia, partner of research institute employee: Figure 4 displays the personal network of Celia, a 32 years old woman who has moved to Seville with her partner, an employee of the research institute. During the interview, her husband was one year into his three-year post-doctoral contract. Either his contract may be extended for another three years or they will move to another location. Celia is currently taking care of their two young kids and also studying for a doctorate.

As is typical of highly mobile individuals, her social support ties are geographically widespread illustrating trails of previous residential mobility. A high proportion of respondents in this community were following their partners through post-doctoral positions in different academic institutions. In fact, when asked how they connected to the city, most respondents' primary response was through their partner. "I feel connected to Seville through my partner's work" (EC community \#74, female, 43 years) said one of the participants. As another said, "it is easy to meet locals through my partner's job" (EC community \#75, female, 30 years). Celia's network mainly consists of co-nationals and other foreigners. The people listed in her network are equally divided 
between three locations: host location, country of origin and other locations. People living in Seville were more likely to be other foreigners. Alters who provide multiplex support are mainly based in her country of origin. Few Spanish people can be observed in her network, although they also provided multiplex support.

In terms of structure, the network is characterized by the interconnection between people living in the country of origin and in other locations, as a result of previous residential mobility. Celia has lived in three other locations before moving to Seville. Family and friends from her country of origin have travelled to visit her in the previous location establishing connections between these two transnational spaces. She also travels rather frequently herself, to visit her family and friends. In fact, having "an airport and a good railway service" (EC community \#83, female, 61 years) was mentioned by one of the other respondents as an important aspect of the city. Within this community, travel between different countries was frequent, for both work and leisure.

Celia's husband (alter \#1) has a central role in her network because he knows everybody. The dominance of this alter in her network coincides in this case with a form of mobility spurred by family needs. Her short residence in Seville explains the low connection between ties from her country of origin, people living in other locations and the low number of Spanish people in her network.

\section{HERE FIGURE 4}

Boris, orchestra musician: Boris, a 55 years old musician, moved to Seville from an Eastern European country more than 20 years ago to work for the classical music orchestra (Figure 5). His network reflects the pattern of residential mobility that has been typically investigated, with no previous mobility circulation and with the aim of permanent settlement in the new location. Multiplex support ties are based in the host location and mainly derived from people born in Spain. The Spanish alter residing in the country of origin is Boris' son, who plays a central role together with the respondent's wife in connecting the network. His son moved to the family's country of origin to pursue his musical studies.

Boris' network is easily distinguished for its density. Most alters knew each other and there are no isolates. People living in other locations are also well connected with people in Seville and in the country of origin. Within this community, such alters tend to be musicians who have moved to other locations.

Despite feeling Seville is his home place, Boris senses he will always be a foreigner in the city, confessing identifying more with the city, and less with the locals. As one respondent said, "I love this city, it is very peaceful... but it has a double face. The people are very nice but very closedminded. I will always be a foreigner here" (musician \#30, male, 55 years). Similar to the other musicians we have interviewed, Boris does not only show a high cultural capital, but he is also highly qualified and has a high standard of living. Musicians commented that their integration in the host location has reshaped the classical music tradition. For instance, Boris also gives music 
classes. According to the musicians interviewed, pedagogy in classical music was almost inexistent until the orchestra was founded and this has improved classical music in the city.

\section{HERE FIGURE 5}

\section{Discussion}

Studying personal networks of mobile individuals shows the importance of social relations in migratory behaviors as suggested by previous research (Boyd, 1989; Lubbers, Molina, Lerner, Brandes, Avila \& McCarty, 2010). In this study we have observed that individuals who envisage permanent settlement in the host society distribute their supportive relationships differently, compared to those who display a more circular mobility patterns between different countries or those who are planning to return soon to their country of origin. This is consistent with previous studies (Maya Jariego \& Holgado, 2015)

In particular, orchestra musicians and Flamenco artists dispose of support networks based in Seville, in which a high number of Spanish people have been incorporated in their network. Musicians from the orchestra were the most settled and integrated in Seville in our sample and their networks seem to reflect this. The time of residence and the expectation to live permanently in the host location appear to be related to a higher structural cohesion, and to more connections with the local population. Their prestigious position in the city as musicians of a high-standard orchestra may also be another reason why they connect so well with locals. On the other hand, the presence of Spanish alters in the networks of Japanese Flamenco artists is possibly related to the fact that through the flamenco community these artists have an easy direct access to Spanish alters. However, their integration in Seville follows a different pattern to other settled individuals. Their connections are community-specific, or subculture-specific, and very few social ties connect them to other social circles outside of their communities. Respondents from these two communities were more likely to sustain contact with their network through frequent face-toface communication.

In contrast, respondents who had either moved recently or who moved for a relatively short period, as in the case of most Erasmus students and partners of researchers, tended to remain highly linked to alters in their country of origin and co-nationals. Their networks are highly transnational reflecting the low durability of their mobility. Temporary or circular mobility provokes these kinds of networks, where strong ties remain available at a distance sustained and facilitated by the wide variety of media available to stay in touch with loved ones. In the case of partners of researchers, we also found a higher presence of people living in other places than the place of origin and the host location, revealing traces of past mobility trajectories. On the other hand, local weak ties (mostly with internationals) are incorporated to serve specific types of support, such as instrumental and socializing support. Short-term and circular mobility also tend to face some barriers related to cultural capital, as for instance, language problems, which could also be a limitation when it comes to inclusion of individuals from the host country in the network. 
In terms of network structure, musicians from the orchestra and partners of researchers were more likely to have interconnected networks in comparison with the other two communities. Researchers and the orchestra members have moved to Seville for employment purposes. Their move to Seville is embedded in formal employment structures, which have facilitated the mobility, provided an economic motivation for moving and in themselves are small cohesive communities, where it is easier to connect to other people and make friends. At the time of the study, both the orchestra and EC institute employed no more than 200 employees. We found no positive relation between the distinctive high education of these respondents (more than $60 \%$ in both communities have a post-graduate degree) and the level of closeness of their networks.

In contrast, the personal networks of the flamenco artists were the sparsest with different subgroups clearly separated from each other. Similarly, the networks of Erasmus were also characterized by a relatively low closeness centrality. The low cohesion in these groups could be interpreted in different ways. In the case of Erasmus students, their recent move to Seville could be the obvious reason for a lower cohesion. In fact, cohesion was mainly produced by the majority of ties living in the country of origin who are highly connected among each other Flamenco artists seem to be strongly connected to the locals through the flamenco world, but at the same, on the periphery of the city in terms of social connection and integration. They demonstrate a high sense of belonging within the flamenco community and a low sense of belonging in the social field outside the Flamenco community. Both flamenco artists and Erasmus students have moved to Seville through large, dispersed relational communities, which, while providing a framework for one's mobility, would possibly not play a major role in one's settlement in a location as small cohesive communities do.

To resume, findings in this study reveal a heterogeneous foreign population in a single place of residence, for which patterns of mobility are reflected in the personal networks of mobile individuals. As highlighted by previous migration research, the time spent in the city seems to have an influence on the degree of settlement of the respondent in the city. However, the degree of settlement in our study was also influenced by another factor: the time expected to live in the city. Respondents with a high expectancy of mobility, whether imminent or in the future, were more likely to sustain strong connections with their transnational ties. Despite of the differences across groups, and congruent with other studies, we found that social support networks are transnational (Albrow, 1997; Fennell, 1997; Horrigan, 2001; Licoppe, 2004; Mok \& Wellman, 2007; Mok, Wellman, \& Carrasco, 2010; Viry, 2012; Wellman, 1996, 2002) and that distant ties are an important source of social support for all cases. Respondents keep contact with these distant ties through periodic visits and frequent communication through media (Boase et al., 2006; Larsen, Urry, \& Axhausen, 2006). Our findings are also consistent with previous observations that highly educated people have a great capacity for maintaining strong relationships with geographically dispersed ties (Viry, 2012). 


\section{Conclusion}

Migration studies have focused primarily on individuals who leave their country of origin to rebuild their lives permanently in another country. Thus, the permanent settlement in the place of reception has become the paradigm to describe the processes of adaptation and social integration of immigrants, often predicting a progressive process of local insertion. However, over the past decades, types of mobility have diversified, and permanent settlement is only one of a vast array of mobility patterns. In our study, we therefore compared the levels of social integration and transnationalism of groups of immigrants with different mobility patterns, as reflected by their support networks. We found that the duration of stay increases the opportunities for the establishment of contacts, while the expectation of permanence becomes an incentive to deepen the new relations (cf. Maya-Jariego \& Armitage, 2007). In our study, we observed this pattern among the musicians of the symphony orchestra who, over time, have been forming a highly cohesive and integrated network, with a comparatively large number of members of the receiving society. However, the other groups in our research showed a differentiated pattern with respect to the model of progressive settlement, where durable transnational ties were key and local ties were mostly added for instrumental and socializing purposes, often as a separate subgroup.

The present research is innovative as it compared four communities of highly-skilled mobile individuals with different mobility patterns residing in a single city. Some of these groups were clearly embedded within organizational structures that facilitated the construction of local ties within the community, whereas others were less embedded within such structures. Future research could explore in depth how the community and organizational contexts in which the international displacement takes place, together with the "relational community" of the cohort of migrants, shape the context of opportunities for relationship building.

\section{References}

Albrow, M. (1997). Travelling beyond local cultures: Socioscapes in a global city. In J. Eade (Ed.), Living the global city: Globalization as local process (pp. 37-55). London: Routledge.

Axhausen, K. W., \& Frei, A. (2008). Contacts in a Shrunken World. Paper presented at the 86th Annual Meeting of the Transportation Research Board, Washington, D.C.

Barrera, M. (1980). A method for the assessment of social support networks in community survey research. Connections, 3, 8-13.

Beaverstock, J. V. (1994). Re-thinking skilled international labour migration: World cities and banking organisations. Geoforum, 25(3), 323-338.

Bidart, C., Degenne, A. \& Grossetti, M. (2011). La vie en réseau. Dynamique des relations sociales. Presses Universitaires de France, Paris.

Bilecen, B. (2014). International student mobility and transnational networks: Palgrave Macmillan UK.

Boase, J., Horrigan, J. B., Wellman, B., \& Rainie, L. (2006). The Strength of Internet Ties. Pew/Internet. http://pewinternet.org/ /media//Files/Reports/2010/PIP-Teens-andMobile-2010-with-topline.pdf 
Bonacich, P. (1972). Factoring and weighting approaches to clique identification. Journal of Mathematical Sociology, 2, 113-120.

Borgatti, S. P., Everett, M., \& Freeman, L. C. (2002). Ucinet for Windows: Software for Social Network Analysis. Harvard, MA: Analytic Technologies

Boyd, M. (1989). Family and Personal Networks in International Migration: Recent Developments and New Agendas. International Migration Review, 23(3), 638-670.

Burt, R. S. (1984). Network items and the general social survey. Social Networks, 6(4), 293-339.

Caplan, G. (1974). Support systems and community mental health: Lectures on concept development: New York, Behavioral Publications.

Cassel, J. (1974). Psychosocial processes and stress: Theoretical formulations. International Journal of Health Services, 4, 471-482.

Castells, M. (2000). The rise of the network society (2nd ed.). Oxford: Blackwell.

Clifford, J. (1994). Diasporas. Cultural Anthropology, 9(3), 302-338.

Cobb, S. (1976). Social support as a moderator of life stress. Psychosomatic Medicine, 38(5), 300-314

Collins, F. L. (2011). Transnational mobilities and urban spatialities: Notes from the Asia-Pacific. Progress in Human Geography. doi: 10.1177/0309132511423126

Dahinden, J. (2010). The dynamics of migrants' transnational formations: Between mobility and locality. In R. Baubock \& T. Faist (Eds.), Diaspora and transnationalism: Concepts, theories and methods (pp. 51-72). Amsterdam: Amsterdam University Press.

Degenne, A., \& Lebeaux, M.-O. (2005). The dynamics of personal networks at the time of entry into adult life. Social Networks, 27(4), 337-358.

Diminescu, D. (2008). The connected migrant: An epistemological manifesto. Social Science Information, 47(4), 565-579.

Domínguez, S., \& Maya-Jariego, I. (2008). Acculturation of Host Individuals: Immigrants and Personal Networks. American Journal of Community Psychology, 42(3), 309-327. doi: 10.1007/s10464-008-9209-5

Featherstone, D., Phillips, R., \& Waters, J. (2007). Introduction: spatialities of transnational networks. Global Networks, 7(4), 383-391. doi: 10.1111/j.1471-0374.2007.00175.x

Fennell, G. (1997). Local lives - distant ties: Researching community under globalized conditions. In J. Eade (Ed.), Living the global city: Globalization as local process (pp. 90109). London: Routledge.

Fischer, C. S. (1982). To dwell among friends: Personal networks in town and city. Chicago: Chicago U P.

Freeman, L. C. (1979). Centrality in social networks: Conceptual clarification. Social Networks, 1(215-239).

Gamper, M., Schönhuth, M., \& Kronenwett, M. (2012). Bringing Qualitative and Quantitative Data Together: Collecting Network Data with the Help of the Software Tool VennMaker. In M. Safar \& K. Mahdi (Eds.), Social Networking and Community Behavior Modeling: Qualitative and Quantitative Measures (pp. 193-213). Hershley: PA.

Geddie, K. (2013). The Transnational Ties that Bind: Relationship Considerations for Graduating International Science and Engineering Research Students. Population, Space and Place, 19(2), 196-208. doi: 10.1002/psp.1751

Granovetter, M. S. (1973). The strength of weak ties. American Journal of Community Psychology, 78, 1360-1380.

Griffith, M., Rogers, A., \& Anderson, B. (Producer). (2013). Migration, time and temporalities: Review and prospect. COMPAS Research Resources Paper. Retrieved from https://www.compas.ox.ac.uk/media/RR-2013-Migration Time Temporalities.pdf

Hayne, D. L., \& South, S. J. (2005). Residential mobility and adolescent violence. Social Forces, 84(1), 361-374.

Hennig, M. (2007). Re-evaluating the Community Question from a German perspective. Social Networks, 29(3), 375-390. doi: http://dx.doi.org/10.1016/j.socnet.2007.01.008 
Herz, A. (2015). Relational constitution of social support in migrants' transnational personal communities. Social Networks, 40, 64-74. doi: http://dx.doi.org/10.1016/j.socnet.2014.08.001

Herz, A., \& Gamper, M. (2012). Möglichkeiten und Grenzen der Erhebung egozentrierter Netzwerke im Online-Fragebogen und über digitale Netzwerkkarten. In M. Gamper, L. Reschke, \& M. Schönhuth (Eds.), Knoten und Kanten 2.0: Soziale Netzwerkanalyse in Medienforschung und Kulturanthropologie, (pp. 57-88): Bielefeld.

Hogan, B., Carrasco, J. A. and Wellman, B. (2007). Visualizing personal networks: working with participant-aided sociograms. Field Methods 19, (2): 116-144.

Hollstein, B. (2011). Qualitative approaches. In J. K. Scott \& P. Carrington (Eds.), The SAGE Handbook of Social Network Analysis (pp. 404-416). London: Sage.

Horrigan, J. B. (2001). The Internet and Community Networks: Case Studies of Five U.S. Cities. Pew/Internet. http://arxiv.org/abs/cs.CY/0109084

King, R. (2012). Theories and typologies of migration: An overview and a primer. In B. Fryklund \& E. Righard (Eds.), Willy Brandt Series of Working Papers in International Migration and Ethnic Relations (Vol. 3/12).

King, R., Findlay, A. M., \& Ahrens, J. (2010). International Student Mobility Literature Review: HEFCE.

Kyle, D. (2000). Transnational peasants. Migrations, networks, and ethnicity in Andean Ecuador. Baltimore: Johns Hopkins University Press.

Larsen, J., Urry, J., \& Axhausen, K. W. (2006). Mobilities, networks, geographies. Aldershot: Ashgate.

Larsen, J., Urry, J., \& Axhaussen, K. (2006). Social networks and future mobilities. Report to the UK Department of Tansport (Lancaster and Zurich) Departement of Sociology. from http://e-collection.ethbib.ethz.ch/eserv/eth:28933/eth-28933-01.pdf

Licoppe, C. (2004). 'Connected' presence: the emergence of a new repertoire for managing social relationships in a changing communication technoscape. Environment and Planning D: Society and Space, 22(1), 135-156.

Lozares, C., Martín, J., Molina, J.L. \& García-Macías, A. (2013). La cohesión-integración versus la fragmentación social desde una perspectiva relacional. Metodología de Encuestas, 15, 57-75.

Lubbers, M. J., Molina, J. L., Lerner, J., Brandes, U., Avila, J., \& McCarty, C. (2010). Longitudinal analysis of personal networks. The case of Argentinean migrants in Spain. Social Networks, 32(1), 91-104.

Lubbers, M. J., Molina, J. L., \& McCarty, C. (2007). Personal Networks and Ethnic Identifications. International Sociology, 22(6), 721-741. doi: $10.1177 / 0268580907082255$

Magdol, L. (2000). The People you Know: The Impact of Residential Mobility on Mothers' Social Network Ties. Journal of Social and Personal Relationships, 17(2), 183-204. doi: $10.1177 / 0265407500172002$

Magdol, L., \& Bessel, D. R. (2003). Social capital, social currency, and portable assets: The impact of residential mobility on exchanges of social support. Personal Relationships, 10(2), 149-170. doi: 10.1111/1475-6811.00043

Malmberg, G. (1997). Time and Space in International Migration. In T. Hammar, G. Brochmann, K. Tamas, \& T. Faist (Eds.), International Migration, Immobility and Development. Multidisciplinary Perspectives (pp. 21-48). Oxford: Berg.

Marin, A., \& Hampton, K. N. (2007). Simplifying the Personal Network Name Generator. Field Methods, 19(2), 163-193. doi: 10.1177/1525822x06298588

Maya Jariego, I. (2002). Tipos de redes personales de los inmigrantes y adaptación psicológica. Redes. Revista hispana para el análisis de redes sociales, 1. 
Maya Jariego, I. (2003). A general typology of personal networks of immigrants with less than 10 years living in Spain. XXIII International Sunbelt Social Network Conference. Cancún (México), 14-17 de febrero de 2003.

Maya Jariego, I. (2004). Sentido de comunidad y potenciación comunitaria. Apuntes de Psicología, 22 (2), 187-211.

Maya Jariego, I. (2006). Web of compatriots: Relationship networks among immigrants. In J. L. Pérez Pont (Ed.), Geografías del desorden. Migración, alteridad y nueva esfera social (pp. 257-276). Valencia: Universidad de Valencia.

Maya Jariego, I., \& Armitage, N. (2007). Multiple sense of community in migration and commuting: The interplay between time, space and relations. International Sociology, 22(6), 743-766.

Maya Jariego, I. \& Holgado, D. (2005). Lazos fuertes y proveedores múltiples de apoyo: comparación de dos formas de representación gráfica de las redes personales. Empiria. Revista de metodología de ciencias sociales, 10, 107-127.

Maya Jariego, I., \& Holgado, D. (2015). Living in the metropolitan area. Correlation of interurban mobility with the structural cohesion of personal networks and the originative sense of community. Psychosocial Intervention, 24(3), 185-190.

Maya-Jariego, I., Holgado, D. \& Lubbers, M.J. (2016). Efectos de la estructura de las redes personales en la red sociocéntrica de una cohorte de estudiantes en transición de la enseñanza secundaria a la universidad. Submitted.

Mayrhofer, W., Sparrow, P., \& Zimmermann, A. (2008). Modern forms of international working. In Michael Dickmann, Paul Sparrow \& Chris Brewster (Eds.). International human resource management: Contemporary issues in Europe, 219-239.

McCarty, C. (2002). Structure in personal networks. Journal of Social Structure, 3(1).

McCarty, C., Molina, J. L., Aguilera, C., \& Rota, L. (2007). A comparison of social network mapping and personal network visualization. Field Methods, 19(2), 145-162.

McCarty, C., \& Wutich, A. (2005). Conceptual and empirical arguments for including or excluding ego from structural analyses of personal networks. Connections, 26, 80-86.

Mok, D., \& Wellman, B. (2007). Did distance matter before the Internet? Interpersonal contact and support in the 1970s. Social Networks, 29(3), 430-461.

Mok, D., Wellman, B., \& Carrasco, J. (2010). Does Distance Matter in the Age of the Internet? Urban Studies, 47(13), 2747-2783. doi: 10.1177/0042098010377363

Molina, J. L., Fernandez, R., Llopis, J., \& McCarty, C. (2008). El Apoyo Social en Situaciones de Crisis: Un estudio de caso desde la perspectiva de la redes personales. Portularia, VIII(1).

Molina, J. L., Maya-Jariego, I. \& McCarty, C. (2014). Giving Meaning to Social Networks: Methodology for Conducting and Analyzing Interviews based on Personal Network Visualizations. In Betina Hollstein \& Silvia Domínguez (Eds.). Mixed Methods Social Network Research. Designs and Applications. Cambridge: Cambridge University Press.

Molina, J. L., Petermann, S., \& Herz, A. (2014). Defining and Measuring Transnational Social Structures. Field Methods, 27(3): 223-243. doi: 10.1177/1525822x14556254

Parreñas, R. S. (2010). Homeward bound: the circular migration of entertainers between Japan and the Philippines. Global Networks, 10(3), 301-323. doi: 10.1111/j.14710374.2010.00288.x

Robertson, S. (2014). The temporalities of international migration: Implications for ethnographic research. In D. Rowe, R. Dobson, \& M. Kelly (Eds.), (Vol. 5): Institute for Culture and Society Occasional Papers Series.

Ryan, L., Sales, R., Tilki, M., \& Siara, B. (2008). Social Networks, Social Support and Social Capital: The Experiences of Recent Polish Migrants in London. Sociology, 42(4), 672690. 
Salganik, M. J., \& Douglas, D. H. (2004). Sampling and Estimation in Hidden Populations Using Respondent-Driven Sampling. Sociological Methodology, 34, 193-239.

Sarason, I. G., Levine, H. M., Basham, R. B., \& Sarason, B. R. (1983). Assessing social support: The social support questionnaire. Journal of Personality and Social Psychology, 44, 127139.

Schönhuth, M., Kronenwett, M., Gamper, M., \& Stark, M. (2012). VennMaker 1.5. Trier. Retrieved from http://www.vennmaker.com

Sheller, M., \& Urry, J. (2006). The new mobilities paradigm. Environment and Planning A, 38(2), 207-226.

Song, L., Son, J., \& Lin, N. (2011). Social support. The Sage handbook of social network analysis, 116-128.

Tardy, C. H. (1985). Social support measurement. American journal of community psychology, 13(2), 187-202.

Urry, J. (2000). Sociology Beyond Societies : Mobilities for Twenty First Century. Florence, KY, USA: Routledge.

Urry, J. (2003). Social networks, travel and talk. The British Journal of Sociology, 54(2), 155-175. doi: 10.1080/0007131032000080186

Urry, J. (2007). Mobilities. Cambridge: Polity.

van der Poel, M. G. M. (1993). Delineating personal support networks. Social Networks, 15(1), 49-70.

Veiel, H. O. F. y Baumann, U. (Eds.) (1992). The meaning and measurement of social support. New York: Hemisphere Publishing.

Vertovec, S. (2003). Migration and Other Modes of Transnationalism: Towards Conceptual Cross-Fertilization. The International Migration Review, 37(3), 641-665.

Viry, G. (2012). Residential mobility and the spatial dispersion of personal networks: Effects on social support. Social Networks, 34(1), 59-72.

Wellman, B. (1979). The community question: The intimate networks of East Yorkers. American Journal of Community Psychology, 84(5), 1201-1231.

Wellman, B. (1996). Are personal communities local? A Dumptarian reconsideration. Social Networks, 18(4), 347-354.

Wellman, B. (1999). The Network Community: An Introduction. In B. Wellman (Ed.), Networks in the global village: Life in contemporary communities (pp. 1-47). Oxford: Westview Press.

Wellman, B. (2001). Physical place and cyberplace: the rise of personalized networking. International Journal of Urban and Regional Research, 25(2), 227-252.

Wellman, B. (2002). Little Boxes, Glocalization, and Networked Individualism. Paper presented at the Revised Papers from the Second Kyoto Workshop on Digital Cities II, Computational and Sociological Approaches.

Wellman, B., \& Wortley, S. (1990). Different strokes from different folks: Community ties and social support. American Journal of Sociology, 96(3), 558-588. 


\begin{tabular}{|c|c|c|c|c|c|c|c|c|c|c|c|}
\hline & & \multicolumn{2}{|c|}{ Flamenco } & \multicolumn{2}{|c|}{ Erasmus } & \multicolumn{2}{|c|}{ IPTS } & \multicolumn{2}{|c|}{ Orchestra } & \multicolumn{2}{|c|}{ Total } \\
\hline & & $f$ & $\%$ & $f$ & $\%$ & $f$ & $\%$ & $f$ & $\%$ & $f$ & $\%$ \\
\hline \multirow[t]{2}{*}{ Gender } & Female & 14 & 73.7 & 21 & 63.6 & 22 & 88 & 9 & 50.0 & 66 & 69.5 \\
\hline & Male & 5 & 26.3 & 12 & 36.4 & 3 & 12 & 9 & 50.0 & 29 & 30.5 \\
\hline \multirow[t]{3}{*}{ Age } & Under 30 & 1 & 5.3 & 33 & 100.0 & 4 & 16 & 1 & 5.6 & 39 & 41.0 \\
\hline & $31-50$ & 15 & 78.9 & - & - & 17 & 68 & 11 & 61.2 & 43 & 45.3 \\
\hline & Over 51 & 3 & 15.8 & - & - & 4 & 16 & 6 & 33.3 & 13 & 13.7 \\
\hline \multirow[t]{4}{*}{ Marital Status } & Single & 10 & 52.6 & 32 & 97.0 & 9 & 36 & 4 & 22.2 & 55 & 57.9 \\
\hline & Married & 6 & 31.6 & 0 & - & 16 & 64 & 10 & 55.6 & 32 & 33.7 \\
\hline & Divorced/Separated & 3 & 15.8 & 1 & 3.0 & 0 & - & 2 & 11.1 & 6 & 6.3 \\
\hline & Other & - & - & - & - & - & - & 2 & 11.2 & 2 & 2.2 \\
\hline \multirow[t]{3}{*}{ Living situation } & Alone & 5 & 26.3 & - & - & - & - & 3 & 16.7 & 8 & 8.4 \\
\hline & Partner / Family & 8 & 42.1 & - & - & 25 & 100 & 15 & 83.3 & 48 & 50.5 \\
\hline & Flat mate & 6 & 31.6 & 33 & 100 & - & - & - & - & 39 & 41.1 \\
\hline \multirow[t]{4}{*}{ Education } & High School & 6 & 31.6 & 20 & 60.6 & 2 & 8 & 0 & 0 & 28 & 29.5 \\
\hline & First Degree & 8 & 42.1 & 11 & 33.3 & 7 & 28 & 7 & 38.9 & 33 & 34.7 \\
\hline & Post-Graduate Degree & 4 & 21.1 & 2 & 6.1 & 14 & 56 & 11 & 61.1 & 31 & 32.6 \\
\hline & Doctorate & 1 & 5.3 & - & - & 2 & 8 & - & - & 3 & 3.2 \\
\hline \multirow[t]{4}{*}{ Years of residence } & $<1$ year & 3 & 15.8 & 32 & 97.0 & 6 & 24 & - & - & 41 & 43.2 \\
\hline & Years 1-5 & 7 & 36.8 & 1 & 3.0 & 17 & 68 & 1 & 5.6 & 26 & 27.4 \\
\hline & Years $6-10$ & 2 & 10.5 & - & - & 1 & 4 & 1 & 5.6 & 4 & 4.2 \\
\hline & & 7 & 36.8 & - & - & 1 & 4 & 16 & 88.9 & 24 & 25.3 \\
\hline \multirow[t]{4}{*}{ Expected time in Seville } & $\begin{array}{l}>10 \text { vears } \\
\text { l do not know }\end{array}$ & 6 & 31.6 & 1 & 3.0 & 6 & 24 & 4 & 22.2 & 17 & 17.9 \\
\hline & Few more months & 3 & 15.8 & 32 & 97 & 5 & 20 & - & - & 40 & 42.1 \\
\hline & $1-5$ years & 4 & 21.1 & - & - & 11 & 44 & 2 & 11.1 & 17 & 17.9 \\
\hline & Indefinitelv & 6 & 31.6 & - & - & 3 & 12 & 12 & 66.7 & 21 & 22.1 \\
\hline
\end{tabular}




\begin{tabular}{lll}
\hline \multicolumn{1}{c}{ Table 2. Name interpreters } & \\
\hline \multicolumn{1}{c}{ Variable } & \multicolumn{1}{c}{ Categories } & Scale \\
\hline Frequency of & Face-to-face & Daily \\
communication & Mobile & Weekly \\
& Email & Monthly, \\
& Social networking sites (SNS) & Yearly/very rarely \\
& VolP (Voice over Internet Protocol & Never \\
\hline Type of relation & Partner & \\
& Family members & \\
& Friend & \\
& Colleague & At the aggregate (i.e. network) \\
& Neighbor & level, each variable indicate the \\
& Other & number of alteri listed per each \\
Duration of tie & Known in the past year & \\
& Known in the past five years & \\
& Known in the past ten years & \\
& Known in the past twenty years & \\
Kocation & Known over 20 years & \\
& Host location & \\
Nationality & Country of origin & \\
& Other & \\
& Spanish & \\
& Compatriots & \\
& Others &
\end{tabular}


Table 3. Means, Oneway ANOVA \& Kruskal Wallis variance of alters mentioned across personal network characteristics per community $(\boldsymbol{N}=95)$

\begin{tabular}{|c|c|c|c|c|c|c|c|c|c|c|}
\hline & Flame & & Erasn & & $\begin{array}{l}\text { Rese } \\
\text { partn }\end{array}$ & cher & Orche & & & \\
\hline & $M$ & SD & $M$ & SD & $M$ & SD & $M$ & SD & $F$ & $H$ \\
\hline Network Comp & tion & & & & & & & & & \\
\hline Location & & & & & & & & & & \\
\hline Seville & 16.6 & 6.2 & 9.9 & 5.6 & 11.4 & 5.5 & 17.0 & 4.6 & $9.6^{\star \star \star *}$ & \\
\hline $\begin{array}{l}\text { Country of } \\
\text { Origin }\end{array}$ & 9.5 & 5.1 & 15.9 & 4.6 & 12.0 & 6.2 & 7.8 & 3.5 & $11.4^{\star * \star *}$ & \\
\hline
\end{tabular}

\section{Nationality}

$\begin{array}{lllllllllll}\text { Spanish } & 11.5 & 4.9 & 2.7 & 2.5 & 7.0 & 5.8 & 12.6 & 5.2 & & 48.3^{* * * *} \\ \text { Co-Nationals } & 13.0 & 5.0 & 20.5 & 6.7 & 15.1 & 6.4 & 10.4 & 4.5 & 13.3^{* * * *}\end{array}$

\section{Role of Alteri}

$\begin{array}{llllllllll}\text { Family } & 5.1 & 3.2 & 5.2 & 3.7 & 6.3 & 3.1 & 5.9 & 3.0 & 3.2 \\ \text { Friends } & 18.9 & 4.3 & 22.3 & 4.7 & 18.7 & 5.0 & 16.8 & 5.8 & 14.7^{* * *}\end{array}$

\section{Duration of tie}

$\begin{array}{llllllllll}\text { Past } 5 \text { years } & 13.6 & 6 . & 19.6 & 5.8 & 14.0 & 5.8 & 4.9 & 4.4 & 26.2^{\star \star \star *}\end{array}$

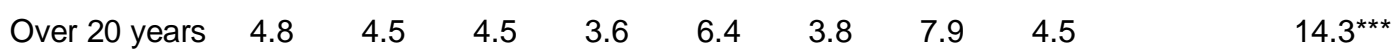

Network Structure

\section{Average Centrality}

$\begin{array}{lccccccccc}\text { Degree } & 25.4 & 14.7 & 30.9 & 9.9 & 28.4 & 7.5 & 33.3 & 13.0 & 7.2 \\ \text { Closeness } & 32.6 & 23.0 & 40.6 & 20.1 & 51.5 & 14.2 & 49.6 & 17.6 & 12.1^{* *} \\ \text { Eigenvector } & 2.8 & 1.3 & 2.9 & 1.3 & 2.9 & 1.3 & 2.7 & 0.7 & 0.3 \\ \text { Betweenness } & 21.5 & 6.2 & 21.0 & 2.5 & 21.8 & 1.8 & 22.1 & 1.8 & 4.6\end{array}$

\section{Frequent communication with alters}

$\begin{array}{lccccccccc}\text { Face-to-face } & 11.1 & 5.6 & 12.2 & 5.5 & 8.1 & 4.1 & 13.1 & 4.7 & 12.7^{*} \\ \text { Mobile } & 4.1 & 3.7 & 8.8 & 4.1 & 6.1 & 4.2 & 9.2 & 3.5 & 22.8^{* * *} \\ \text { Email } & 3.6 & 4.6 & 2.6 & 3.2 & 5.4 & 4.0 & 4.3 & 4.6 & 10.5^{*} \\ \text { SNS } & 2.6 & 2.8 & 15.6 & 6.0 & 3.0 & 3.4 & 2.6 & 2.4 & 59.5^{* * * *} \\ \text { VOIP } & 0.8 & 1.3 & 4 & 3.3 & 2.0 & 2.4 & 1.3 & 1.5 & 18.8^{* * * *} \\ & \end{array}$


Table 4. Cluster Centroids for Network Properties $(N=90)$

Network profiles (Clusters)

\begin{tabular}{lcccc} 
& Dense & Host & Distant & Sparse \\
& $(\mathrm{n}=13)$ & $(\mathrm{n}=21)$ & $(\mathrm{n}=34)$ & $(\mathrm{n}=22)$ \\
Average closeness centrality & 51.1 & 26.4 & 31.0 & 18.4 \\
$\mathbf{N}$ alters living in country of origin & 12 & 6 & 14 & 14 \\
$\mathbf{N}$ friends & 19 & 17 & 22 & 7 \\
$\mathbf{N}$ Spanish alteri & 8 & 15 & 4 & \\
\hline
\end{tabular}




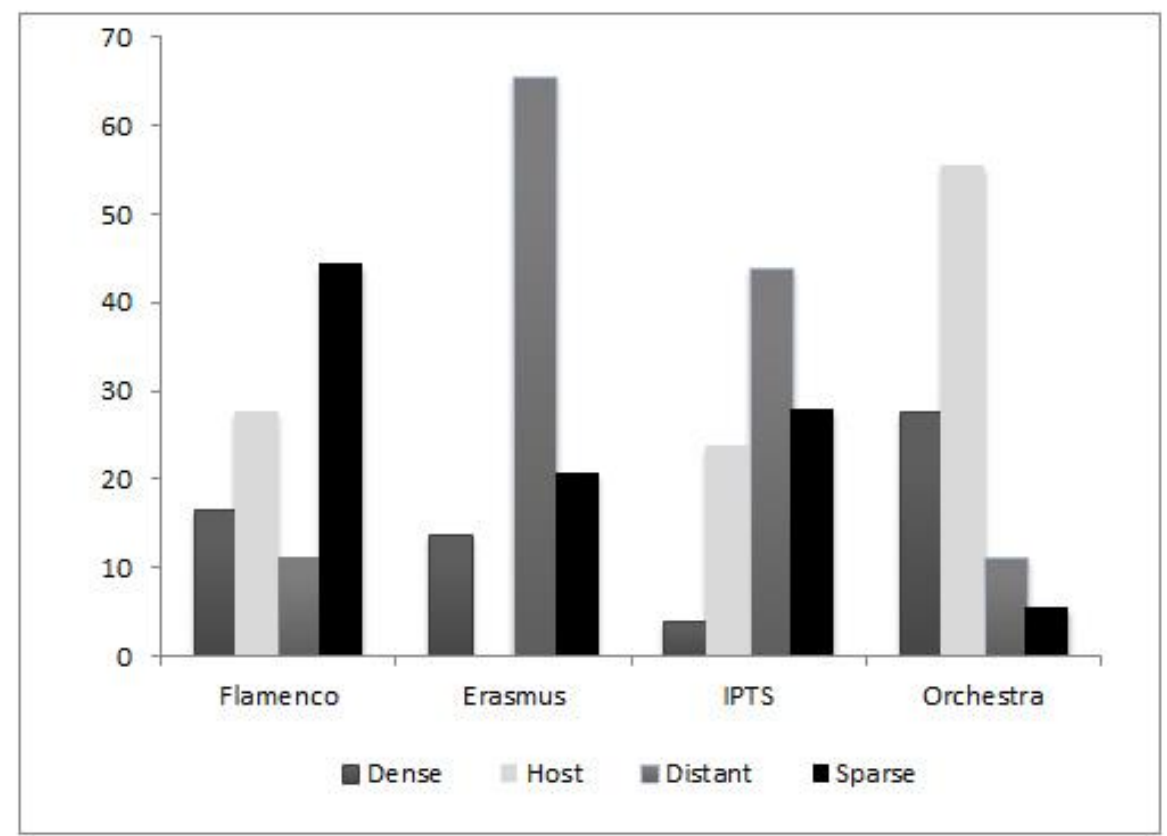

Figure 1. 


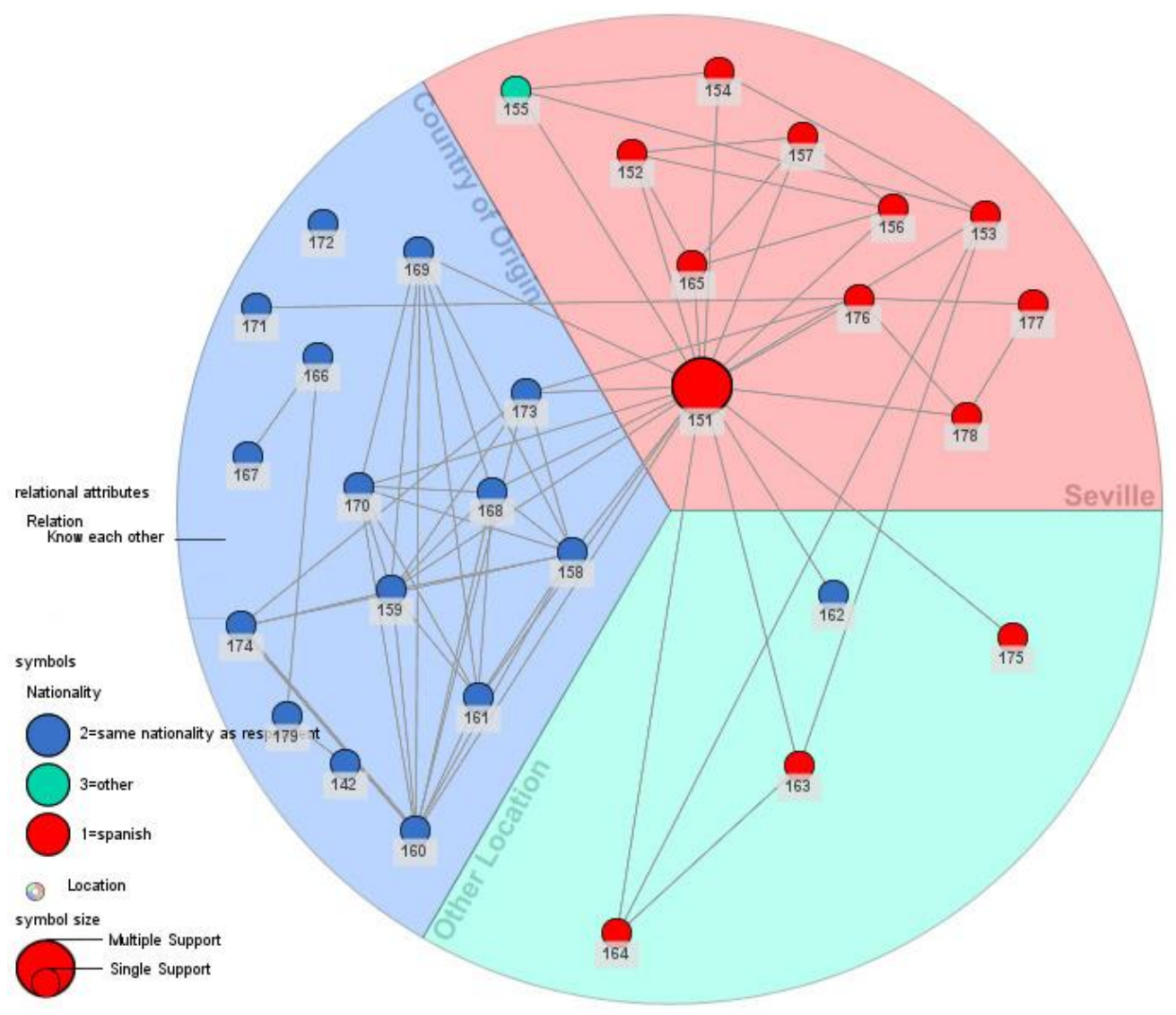

Figure 2. Flamenco 


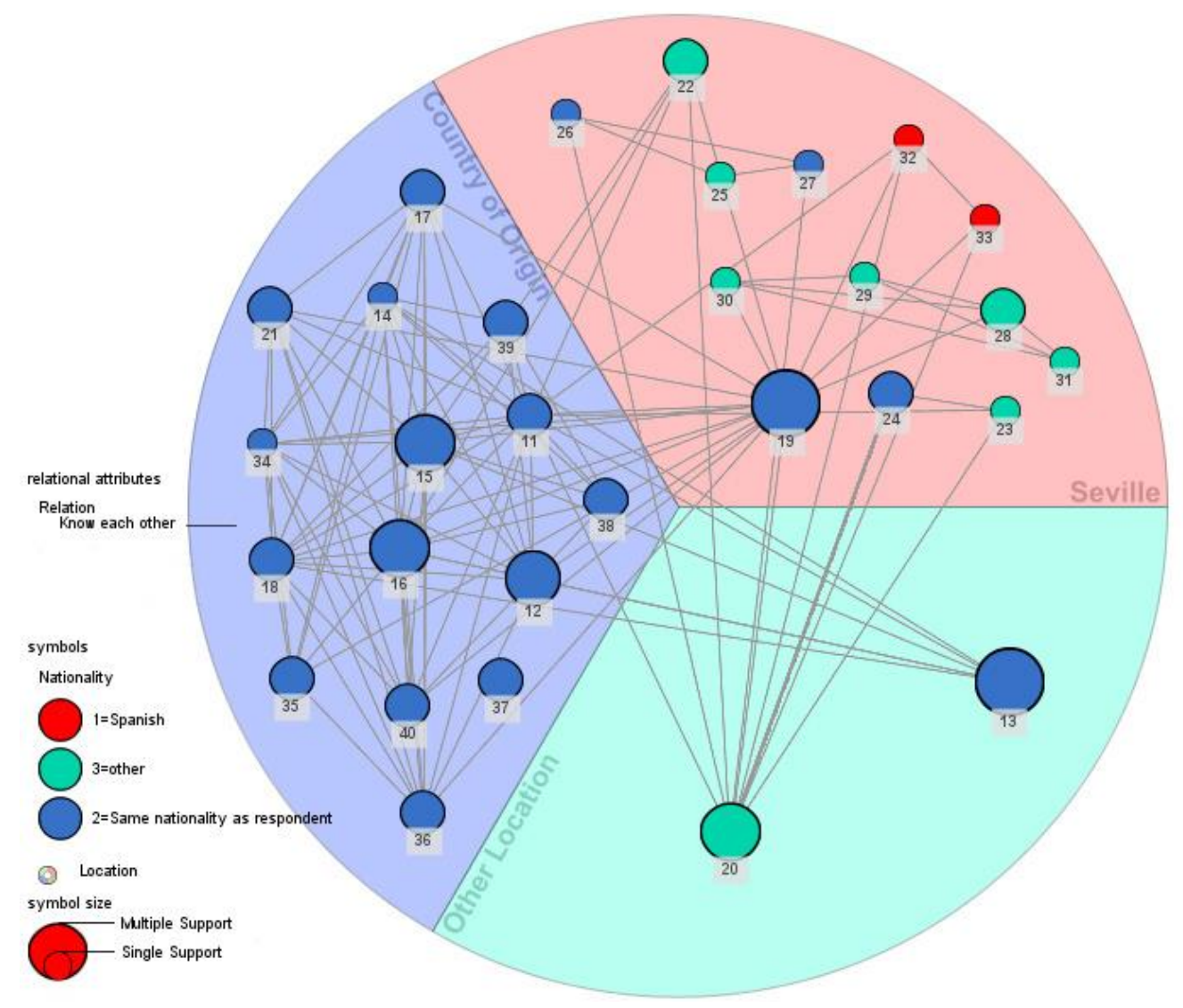

Figure 3. Erasmus 


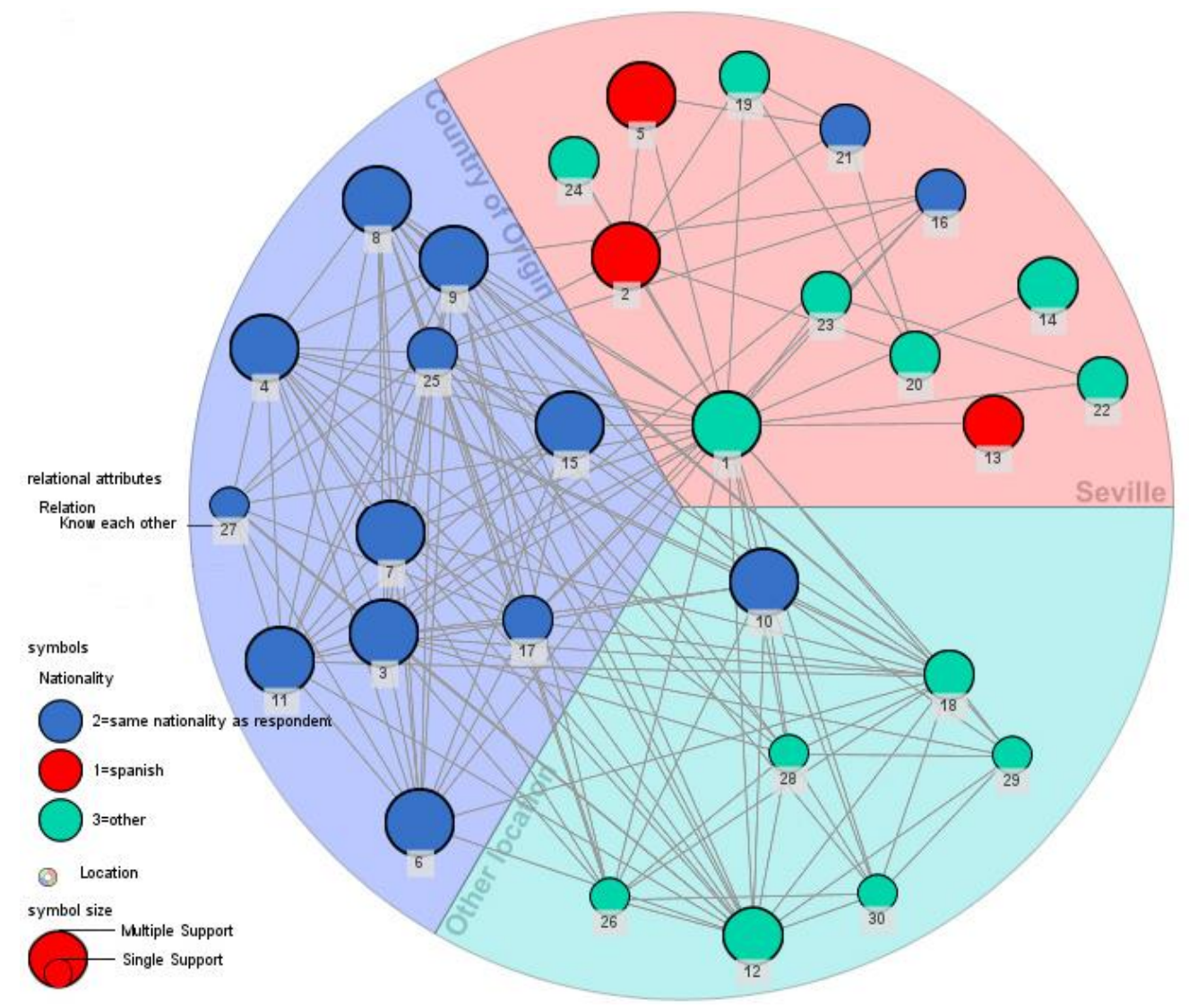

Figure 4. European Commission 


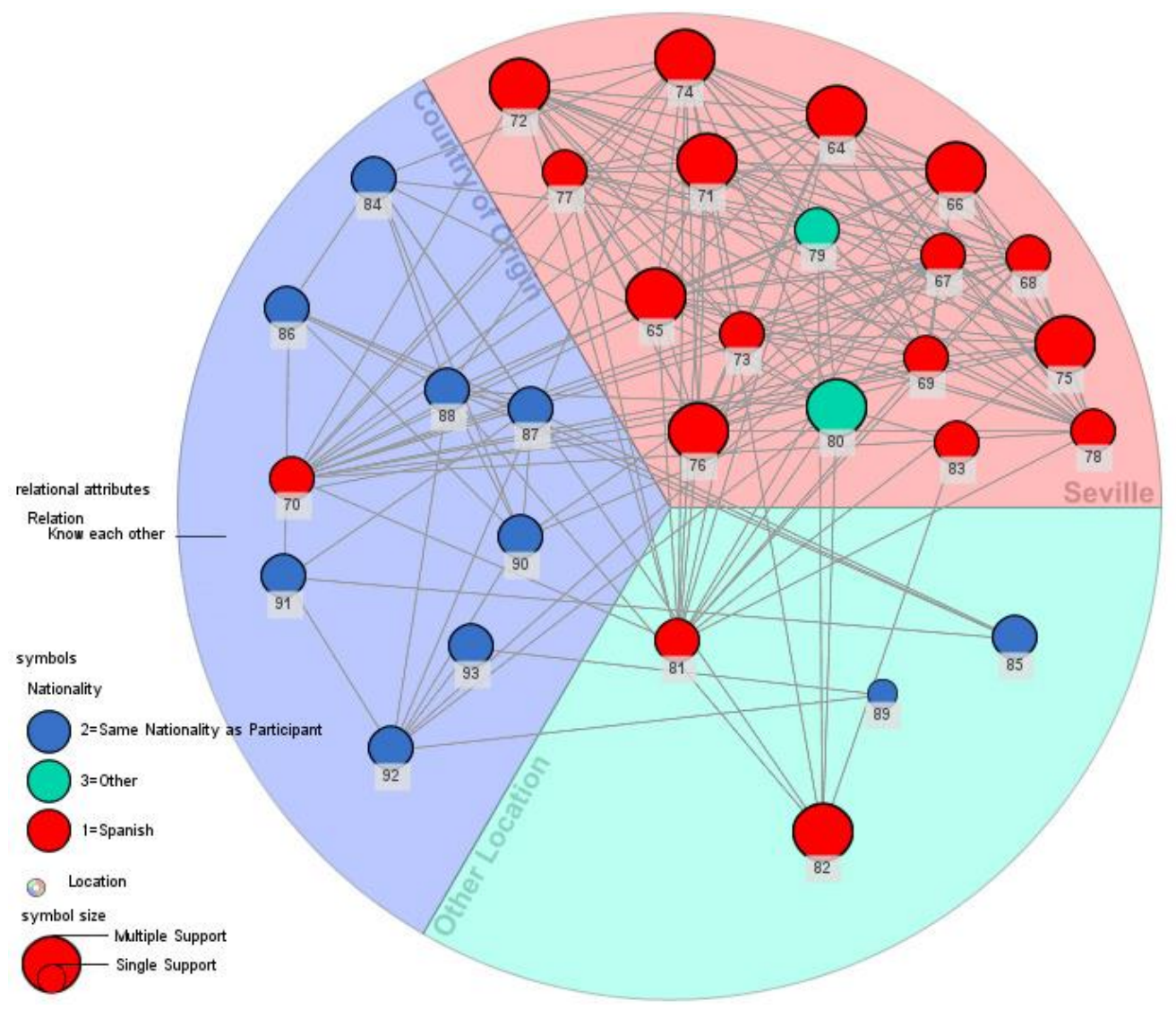

Figure 5. Orchestra 